\title{
Control of Health Care-Associated Infections
}

\author{
N. Joel Ehrenkranz, MD, Ann Macintyre, DO, Patricia R. Hebert, MSN, PhD, \\ Wendy R. Schneider, MSN, CCRC, and Charles H. Hennekens, MD, DrPH
}

Florida Atlantic University, Boca Raton, FL, USA.

$\mathrm{J}$ Gen Intern Med 26(3):238

DOI: $10.1007 / \mathrm{s} 11606-010-1604-6$

(c) Society of General Internal Medicine 2010

Authors' Reply: We were gratified to learn of the outstanding efforts of Drs. Arya, N. Agarwal, and S. Agarwal to promptly identify and control health care-associated infections (HAI). The optimal prompt identification and control of HAIs should include their laudable strategies as well as several others as adjuncts, not alternatives, to educational efforts targeted for established as well new health care providers. A multidisci-

Published online December 22, 2010 plinary approach to the vigorous implementation and maintenance of proper infection control procedures is necessary to win both the battles and the war against HAI.

Conflict of Interest: None disclosed.

Ethical Clearance: Not required.

Financial Support: None.

Corresponding Author: Charles H. Hennekens, MD, DrPH; Florida Atlantic University, 777 Glades Road, Research Park, Bldg 3848, Suite 310, Boca Raton, FL 33431-0991, USA (e-mail: chenneke@fau. edu). 